\title{
COMPARATIVE ANALYSIS \\ OF PASTEURELLA MULTOCIDA STRAINS ISOLATED FROM BOVINE RESPIRATORY INFECTIONS
}

\author{
BOGLÁRKA SELLYEI ${ }^{1 *}$, ZSUZSANNA RÓNAI², SZILÁRd JÁNOSI ${ }^{2}$ \\ and LÁSZLÓ MAKRAI ${ }^{3}$ \\ ${ }^{1}$ Institute for Veterinary Medical Research, \\ Centre for Agricultural Research, Hungarian Academy of Sciences, Budapest, Hungary \\ ${ }^{2}$ Veterinary Diagnostic Directorate, National Food Chain Safety Office, Budapest, Hungary \\ ${ }^{3}$ Department of Microbiology and Infectious Diseases, Faculty of Veterinary Science, \\ Szent István University, Budapest, Hungary
}

(Received: 12 August 2015; accepted: 10 October 2015)

\begin{abstract}
Bovine respiratory disease (BRD) is the leading cause of significant economic losses in the intensive beef industry worldwide. Beside numerous risk factors Pasteurella multocida, which is regarded as a secondary pathogen, may play a role in the development of the disease. Previous studies of strains from swine pneumonia revealed that there are a few clones associated with clinical disease, suggesting that some strains may be more virulent than others. This linkage may be true in the BRD, however composition of $P$. multocida populations in the herds are slightly characterized. Thus, we decided to perform phenotypic and genotypic characterisation of strains isolated from calves with respiratory infection at 31 different herds in Hungary. The results demonstrated the presence of two dominant strain types. At the identical taxonomic background ( $P$. multocida subsp. multocida) with slight phenotypic variability they could be separated by trehalose fermentation capacity, $\alpha$-glucosidase activity and molecular fingerprint patterns of ERIC- and M13-PCR. Independent prevalence and geographical origin of the strain types may refer to their significance in the illness, but their comparison with strains isolated from healthy individuals is taken into consideration.
\end{abstract}

Keywords: Pasteurella multocida, bovine respiratory disease, ERIC-PCR, M13-PCR, trehalose fermentation capacity, $\alpha$-glucosidase activity

*Corresponding author; E-mail: sellyei.boglarka@agrar.mta.hu 


\section{Introduction}

The economic losses caused by bovine respiratory disease (BRD) far exceed those due to gastrointestinal problems in calf rearing. It is a major health problem in cattle herds both locally and internationally [1]. The BRD is a multifactorial disease; virus (BVDV, BRSV, PI3) or bacterial infections (Pasteurella multocida, Mannheimia heamolytica, Histphilus somni, Trueperella pyogenes, Mycoplasma bovis) beside many other predisposing factors may be involved in its development. $P$. multocida has been known to be associated with this disease since the early 1950s [2]. As P. multocida is a common inhabitant of the upper airways, it has long been considered to be a secondary pathogen and its exact role in the infection has not been cleared. Recently, the recurrence of BRD outbreaks despite vaccination against other pathogens, and the high $P$. multocida isolation rate from serious illnesses drew attention to its putative significance [3-5]. The respiratory diseases caused by $P$. multocida affect both calves (ECP - enzootic calf pneumonia) and young cattle (shipping fever). The differentiation of the two forms is slightly arbitrary. While ECP manifests within the first 6 months of life (calves contract disease from carrier dams or other herd members), the shipping fever occurs following exhaustive transporting to the stores of livestock-markets, where animals from different herds mingle, and their immune response is diminished due to stress and other predisposing factors. In the two (types of) diseases the clinical symptoms are similar: fever, lethargy, anorexia, coughing, nasal discharge and dyspnoea. They are manifestations of the chronic pneumonia and/or pleuritis induced by $P$. multocida. Most of the calves suffering from pneumonia will die despite treatment or have to be removed from the herd, while in heifers mortality is less significant, the disease mainly manifests in a reduction of weight gain, milk yield, and problems of the meat quality or fertility [1].

The epidemiology of $P$. multocida strains associated with BRD represents a poorly studied research topic so far. There is little knowledge about whether the various commensal strains or pathogenic clone(s), differ from each other in their innate abilities induce disease, or how they take part in it; moreover there is no information about the relationship of strains causing infections in different age groups. Therefore detailed phenotypic and genotypic characterisation of P. multocida strains isolated from diseased animals of Hungarian cattle herds was carried out in order to explore the diversity of the bacterial population. 


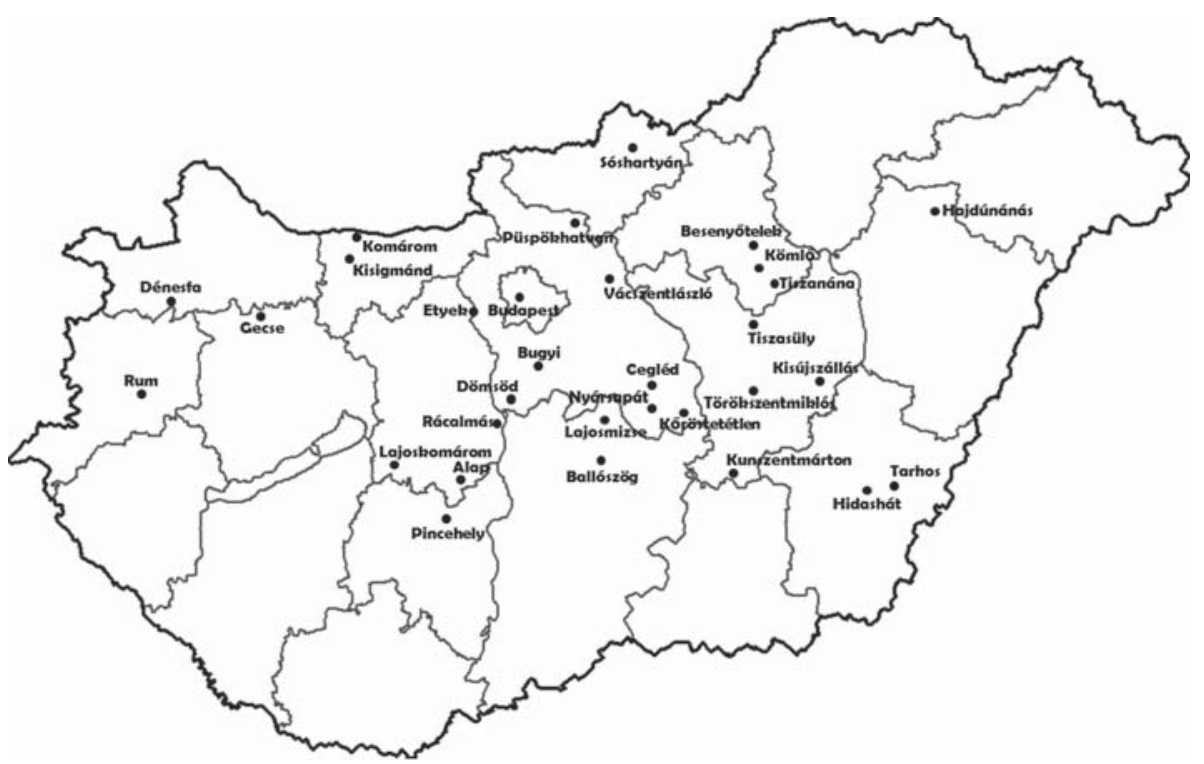

Figure 1. Geographical locations of the sampled bovine populations in Hungary

\section{Materials and Methods}

\section{Bacterial strains}

The studied 31 P. multocida strains were collected from different Hungarian cattle herds between 2006 and 2011 (Figure 1). Twenty-six strains were isolated from lungs of heifers and five from nasal swabs (P930, and P931) and lungs (P929, P932, and P933) of calves.

Following bacteriological identification, the strains were stored in $20 \%$ skim milk powder solution (LAB M Ltd., Bury, Lancashire, UK) at $-70{ }^{\circ} \mathrm{C}$. For detailed examinations they were streaked on Columbia agar plate (LAB M Ltd., Bury, Lancashire, UK) supplemented with 5\% defibrinated sheep blood. The plates were incubated for 24 hours at $37^{\circ} \mathrm{C}$, then separated colonies were inoculated onto brain-heart infusion broth (LAB M Ltd., Bury, Lancashire, UK) for biochemical studies and streaked on dextrose-starch agar plate (LAB M Ltd., Bury, Lancashire, UK) for serological examinations. 


\section{Phenotypical characterisation}

Biochemical features

In the biochemical tests beside indole production, urease-, ornithine-decarboxilase-, and $\alpha$-glucosidase activities and sugar (arabinose, glucose, lactose, sucrose, trehalose, maltose and xylose) or sugar-alcohol (dulcitol, sorbitol) fermentation abilities [6] were detected (Fermentas, Thermo Fisher Scientific, Waltham, WA, USA). Based on the results the strains were grouped in biovars [7-9]. The ingredients of solutions and methods were described previously by Varga et al. [10].

\section{Serological features}

The capsular type of the strains was identified by PCR according to the method of Townsend et al. [11]. The somatic serogroups were studied with agar gel precipitation test [12].

\section{Molecular characterisation}

For molecular examination, the bacterial DNA was extracted by Chelex' method [13]. The basic features were detected by species, toxin, and capsule A specific multiplex PCR [9, 14]. Capsule types beyond A were identified by multiplex capsular PCR [11]. The subgroups of the strains were classified with PCR-RFLP on the 16S rRNA gene [15]. The relationship of strains was examined with ERIC (enterobacterial repetitive intergenic consensus) - [16] and M13 PCRs $[17,18]$.

The reaction mixtures for ERIC and M13 PCRs were prepared in $25 \mu \mathrm{l}$ : $1 \times$ PCR buffer (Fermentas), $3.5 \mathrm{mM} \mathrm{MgCl}_{2}, 200 \mathrm{nM}$ dNTP-mix, 25 pmol primers, 2.5 U Dream Taq (Fermentas), and $5 \mu$ template DNA. The reaction conditions were: pre-denaturation 3 minutes at $93{ }^{\circ} \mathrm{C}$, then 30 cycles at $93{ }^{\circ} \mathrm{C} 30 \mathrm{sec}, 50{ }^{\circ} \mathrm{C}$ $1 \mathrm{~min}$, and $72{ }^{\circ} \mathrm{C} 70 \mathrm{sec}$, and the final polymerisation step for 5 minutes at $72{ }^{\circ} \mathrm{C}$.

The PCR fragments were detected by gel electrophoresis on $2 \%$ or $1.5 \%$ agarose gel. The molecular patterns were evaluated with the Hyper Ladder II DNA molecular marker (50-2000 bp, Bioline, Massachusetts, US). The representation of the generated distance matrix using UPGMA (unweighted pair-group method with arithmetic mean) algorithm was carried out with TREECON software package [19]. 


\section{Results and Discussion}

Although, the association of $P$. multocida with respiratory diseases in various host species (swine, poultry, and rabbits) is well-known, the correlation of this pathogen with BRD is poorly studied [20,21]. In this study detailed phenotypic and genotypic characterization was carried out on 31 bovine $P$. multocida strains isolated predominantly from lungs of cattle suffered from pneumonia in different Hungarian herds. The results showed that the strains possessed similar serological, biochemical and genetic features without reference to their origin. Serologically they mainly belonged to serogroups A3 (14/31), A3,4 (7/31) or A4 (4/31), which are considered to be typical for strains causing pneumonia in both cattle and pigs $[22,18]$. However, some strains belonging to serogroups D and A1 were detected as well. These serogroups are known to be associated with diseases in swine or poultry (fowl cholera), respectively. Interestingly, the fermentation properties of the strains were fairly uniform in contrast to the diversity of strains from other hosts (swine, rabbits, and poultry). Eighty percent of all strains belonged to two biochemical variants (biovar 2 and 3). These biovars differed from each other only in their trehalose fermentation ability. The dominance of these two types is characteristic among strains from other host species as well. In small number, five other biovars $(1,12,4,7$, and 9) were detected, differing from the two dominant types only in some biochemical features (Table I).

Table I. Fermentation patterns of the studied $P$. multocida strains

\begin{tabular}{|c|c|c|}
\hline & & \\
\hline Biovars & 3 & 2 \\
\hline No. of strains & (12) & (13) \\
\hline ODC & + & $+!$ \\
\hline \multicolumn{3}{|l|}{ Fermentation } \\
\hline $\mathrm{D}(-)$ Arabinose & - & - \\
\hline Lactose & $-\#$ & - \\
\hline Maltose & - & - \\
\hline Trehalose & - & + \\
\hline $\mathrm{D}(+)$ Xylose & $+\int$ & $+\S$ \\
\hline Dulcitol & - & - \\
\hline $\mathrm{D}(-)$ Sorbitol & + & $+\dagger$ \\
\hline
\end{tabular}


Notably, the presence of $\alpha$-glucosidase activity, which has not been studied in this context earlier, correlated with the trehalose fermentation ability of the strains, except for P1185 and P1006. This biochemical feature was considered earlier as a tool for the differentiation of P. multocida subsp. multocida and septica, the two dulcitol-negative subspecies [23]. However, the results of molecular studies have not supported this coherence clearly.

In the $16 \mathrm{~S}$ ribosomal RNA gene PCR-RFLP assay, aiming the differentiation of subspecies, the strains displayed identical profiles, which is typical of P. multocida subsp. multocida [15]. For mapping of the genetic relationship of these highly similar strains, different molecular fingerprint methods are required. In this study the M13 minisatellite marker assay based on the comparative study of molecular methodological approaches of Taylor [21] and the ERIC (enterobacterial repetitive intergenic consensus) -PCR, based on own experience [24], were chosen. The results of genotypic studies were correlated with each other and with the results of phenotypic characterisation as well (Figure 2). Both approaches sorted the strains into two major sub-populations. In each group some features seem to be characteristic consistently. Biovar 2 strains fermented trehalose and had $\alpha$-glucosidase activity, belonged to the same ERIC-PCR group and presented B pattern in M13 PCR; while biovar 3 strains were unable to ferment trehalose, missed $\alpha$-glucosidase activity, and displayed M13 A pattern.

It is worth considering that all strains in the first group originated from lungs, while strains isolated from the nasal cavity and non-respiratory tract as commensals (milk, vagina, or fetus - unpublished data) belonged to the latter group.

Outside of the two main types, the M13 minisatellite marker PCR identified a few subgroups with various molecular profiles (Figure 3). The various molecular types could be associated with different biochemical characteristics, that is biovars: biovar 9 with B2, the toxin-producing strains with A1 and A2, and strains with capsule type D or F (not presented) with B1.

\section{Conclusions}

In our study the P. multocida strains isolated from the respiratory tract of diseased cattle were highly similar in phenotypic and genotypic features, as well, regardless of their geographical origin. The detected lack of diversity, usual for other hosts, alludes to the potential significance of each strain type. The used various methods confirmed irrespectively the presence of two dominant strain types within the bovine $P$. multocida population. For the clarification of their 


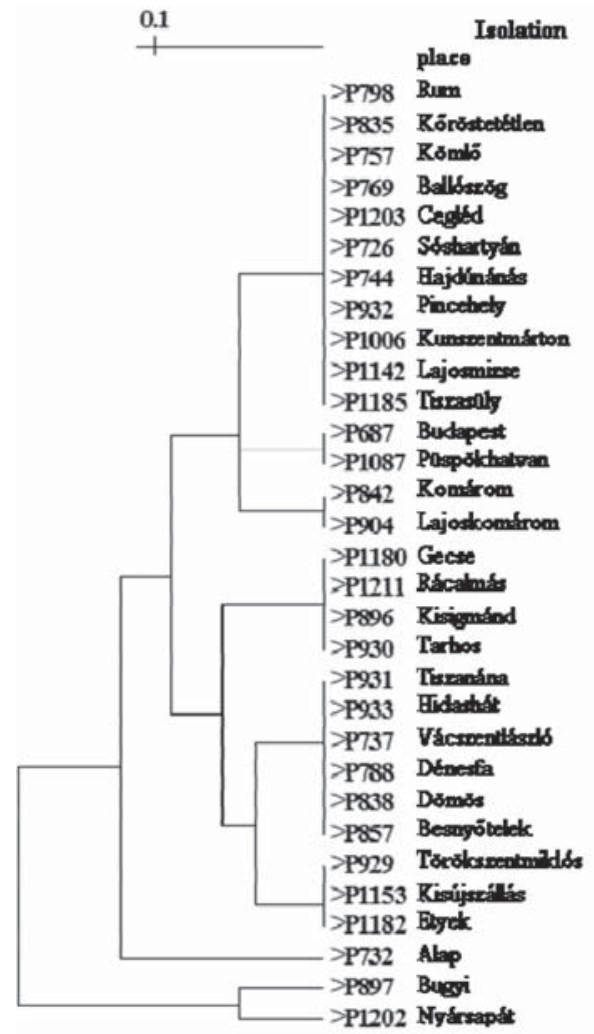

\begin{tabular}{|c|c|c|c|}
\hline year & Serogroup & Biovar & $\begin{array}{l}\text { MI3 } \\
\text { PCR }\end{array}$ \\
\hline 2007 & $A 3$ & 2 & B \\
\hline 2007 & A3,4 & 2 & B \\
\hline 2007 & A3 & 2 & B \\
\hline 2007 & $\mathrm{~A}^{3}$ & 9 & B2 \\
\hline 2011 & $\mathrm{~A}^{3}$ & 2 & B \\
\hline 2006 & $A^{3}$ & 2 & B \\
\hline 2007 & A- & 9 & B2 \\
\hline 2006 & A1 & 2 & B \\
\hline 2009 & A4 & 2 & B \\
\hline 2010 & $A^{3}$ & 2 & B \\
\hline 2010 & A4 & 2 & B \\
\hline 2006 & A3,4 & 2 & B \\
\hline 2009 & A3,4 & 2 & B \\
\hline 2007 & $\mathrm{~A} 3$ & 2 & B \\
\hline 2008 & A3,4 & 2 & B \\
\hline $\begin{array}{l}2010 \\
2011\end{array}$ & $\begin{array}{l}\mathrm{A} 3,4 \\
\mathrm{~A} 4\end{array}$ & $\begin{array}{l}3 \\
3\end{array}$ & $\begin{array}{l}\mathbf{A} \\
\mathbf{A}\end{array}$ \\
\hline 2008 & A- & 12 & $\mathbf{A}$ \\
\hline 2008 & A4 & 3 & $\mathbf{A}$ \\
\hline $\begin{array}{l}2008 \\
2005\end{array}$ & $\begin{array}{l}\text { A3 } \\
\text { A3,4 }\end{array}$ & $\begin{array}{l}3 \\
3\end{array}$ & $\begin{array}{l}\mathbf{A} \\
\mathbf{A}\end{array}$ \\
\hline 2007 & $A 3$ & 3 & A \\
\hline 2007 & $A^{3}$ & 3 & $\mathbf{A}$ \\
\hline 2007 & $A_{3}$ & 3 & $\mathbf{A}$ \\
\hline 2008 & A3 & 3 & $\mathbf{A}$ \\
\hline 2008 & D- & 3 & B1 \\
\hline $\begin{array}{l}2010 \\
2010\end{array}$ & $\begin{array}{l}\text { D3 } \\
\text { D- }\end{array}$ & $\begin{array}{l}3 \\
3\end{array}$ & $\begin{array}{l}\text { B1 } \\
\text { B1 }\end{array}$ \\
\hline 2007 & A3,4 & 1 & B \\
\hline 2008 & A3 & 7 & Al \\
\hline 2011 & A3 & 4 & A2 \\
\hline
\end{tabular}

Figure 2. Comparision of genotypic (M13-, and ERIC PCR) and phenotypic features (serological and biochemical) of studied bovine $P$. multocida strains. The similarity dendogram was constructed by unweighted pair group method with averages (UPGMA) based on ERIC-PCR patterns

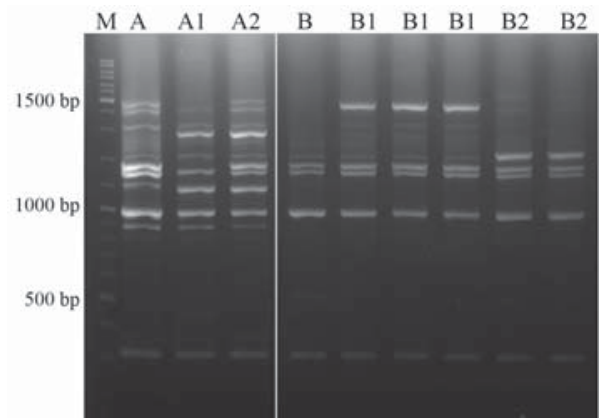

Figure 3. Detected fingerprint profiles generated by M13 PCR

Patterns A and B - most frequent profiles

Patterns A1 and A2 - profiles of toxin-producing strains

Pattern B1 - profiles of strains with capsule type D 
role in the disease process comparison with strains isolated from healthy animals is required.

For such studies, the 16S rRNA gene based PCR-RFLP, and examination of some phenotypic features (trehalose fermentation, and the $\alpha$-glucosidase activity), along with high-resolution molecular methods are recommended for strain categorization.

\section{Acknowledgements}

This project was supported by the Hungarian Scientific Research Fund (OTKA PD 101091) and the 'János Bolyai' Research Scholarship of the Hungarian Academy of Sciences to B. Sellyei. The authors wish to thank Levente Szeredi at the Veterinary Diagnostic Directorate, National Food Chain Safety Office, Budapest, Hungary for the helpful collaboration in the sample collection.

\section{Conflict of Interest}

No conflict of interest.

\section{References}

1. Ózsvári, L., Muntyán, J., Berkes, Á.: Financial losses caused by bovine respiratory disease (BRD) in cattle herds. MÁL 5, 259-264 (2012).

2. Carter, G. R.: Observations on the pathology and bacteriology of shipping fever in Canada. Can J Comp Med Vet Sci 18, 359-364 (1954).

3. Nikunen, S., Härtel, H., Orro, T., Neuvonen, E., Tanskanen, R., Kivelä, S. L., Sankari, S., Aho, P., Pyörälä, S., Saloniemi, H., Soveri, T.: Association of bovine respiratory disease with clinical status and acute phase proteins in calves. Comp Immunol Microbiol Infect Dis 30, 143-151 (2007).

4. Pardon, B., De Bleecker, K., Dewulf, J., Callens, J., Boyen, F., Catry, B., Deprez, P.: Prevalence of respiratory pathogens in diseased, non-vaccinated, routinely medicated veal calves. Vet Rec 169, 278 (2011).

5. Welsh, R. D., Dye, L. B., Payton, M. E., Confer, A. W.: Isolation and antimicrobial susceptibilities of bacterial pathogens from bovine pneumonia: 1994-2002. J Vet Diagn Invest 16, 426-431 (2004).

6. Sadler, D. F, Ezzell, J. W. Jr, Keller, K. F., Doyle, R. J.: Glycosidase activities of Bacillus anthracis. J Clin Microbiol 19, 594-598 (1984).

7. Blackall, P. J., Pahoff, J. L., Bowles, R.: Phenotypic characterization of Pasteurella multocida isolates from Australian pigs. Vet Microbiol 57, 355-360 (1997). 
8. Fegan, N., Blackall, P. J., Pahoff, J. L.: Phenotypic characterization of Pasteurella multocida isolates from Australian poultry. Vet Microbiol 47, 281-286 (1995).

9. Sellyei, B., Varga, Z., Pné Samu, K., Magyar, T.: Characterisation of Pasteurella multocida strains isolated from rabbits. MÁL 130, 396-403 (2008).

10. Varga, Zs., Sellyei, B., Magyar, T.: Phenotypic and genotypic characterisation of Pasteurella multocida strains isolated from pigs in Hungary. Acta Vet Hung 55, 425-434 (2007).

11. Townsend, K. M., Frost, A. J., Lee, C. W.: Genetic organisation of Pasteurella multocida cap loci and development of a multiplex capsular PCR typing system. J Clin Microbiol 39, 924-929 (2001).

12. Heddleston, K. L., Gallager, J. E., Rebers, P. A.: Fowl cholera: Gel diffusion precipitin test for serotyping Pasteurella multocida from avian species. Avian Dis 16, 925-936 (1972).

13. Sellyei, B., Bányai, K., Magyar, T.: Characterization of the $p t f A$ gene of avian Pasteurella multocida strains by allele specific polymerase chain reaction. J Vet Diagn Invest 22, 607-610 (2010).

14. Townsend, K. M., Frost, A. J., Lee, C. W., Papadimitriou, J. M., Dawkins, H. J.: Development of PCR assays for species- and type-specific identification of Pasteurella multocida isolates. J Clin Microbiol 36, 1096-1100 (1998).

15. Sellyei, B., Wehmann, E., Magyar, T.: Sequencing-independent method for the differentiation of the main phylogenetic lineages of Pasteurella multocida. J Vet Diagn Invest 24, 735-738 (2012).

16. Versalovic, J., Koeuth, T., Lupski, J. R.: Distribution of repetitive DNA sequences in eubacteria and application to fingerprinting of bacterial genomes. Nucl Acids Res 19, 6823-6831 (1991).

17. Dabo, S. M., Confer, A. W., Lu Y. S.: Single primer polymerase chain reaction fingerprinting for Pasteurella multocida isolates from laboratory rabbits. Am J Vet Res 61, 305-309 (2000).

18. Taylor, J. D., Fulton, R. W., Dabo, S. M., Lehenbauer, T. W., Confer, A. W.: Comparison of genotypic and phenotypic characterization methods for Pasteurella multocida isolates from fatal cases of bovine respiratory disease. J Vet Diagn Invest 22, 366-375 (2010).

19. Van De Peer, Y., De Wachter, Y.: TREECON for Windows: A software package for the construction and drawing of evolutionary trees for the Microsoft Windows environment. Comput Applic Biosci 10, 569-570 (1994).

20. Hotchkiss, E. J., Hodgson, J. C., Schmitt-van de Leemput, E., Dagleish, M. P., Zadoks, R. N.: Molecular epidemiology of Pasteurella multocida in dairy and beef calves. Vet Microbiol 151, 329-335 (2011).

21. Taylor, J. D.: Molecular epidemiology of Pasteurella multocida respiratory disease in beef cattle. PhD thesis, Oklahoma State University Center for Veterinary Health Sciences, 2008, pp. 1-140.

22. Ross, R. F.: Pasteurella multocida and its role in porcine pneumonia. Anim Health Res Rev 7, 13-29 (2007).

23. Hunt Gerardo, S., Citron, D. M., Claros, M. C., Fernandez, H. T., Goldstein, E. J.: Pasteurella multocida subsp. multocida and Pasteurella multocida subsp. septica differentiation by PCR fingerprinting and $\alpha$-glucosidase activity. J Clin Microbiol 39, 2558-2564 (2001).

24. Sellyei, B., Varga, Z., Ivanics, E., Magyar, T.: Characterisation and comparison of avian Pasteurella multocida strains by conventional and ERIC-PCR assays. Acta Vet Hung 56, 429-440 (2008). 